\title{
TRIBUNAL DE CONTAS DO PARANÁ: INSTITUIÇÃO, POLÍTICA E HISTÓRIA
}

(1947-2017)

\author{
Fernando Marcelino Pereira ${ }^{1}$
}

\begin{abstract}
Resumo: Na Sociologia e na Ciência Política brasileira nota-se que existe um grande foco na pesquisa sobre os poderes Executivos e Legislativos, seja federal, estadual ou municipal. Entretanto, o poder Judiciário e as instituições de controle, como o Tribunal de Contas e o Ministério Público, são pouco pesquisadas. Neste artigo proponho uma análise do Tribunal de Contas do Paraná, com foco em seus aspectos funcionais e políticos, para encontrarmos sua articulação com a história do Paraná. Trata-se de uma instituição com pouca exposição social, sem muito destaque na opinião pública local. Apesar de ser popularmente conhecido como local de coagulação de disputas e deliberações acerca de aspectos relevantes da vida política estadual e municipal, muito pouco se sabe sobre o poder que o Tribunal de Contas exerce sobre os outros poderes e sobre a sociedade, quem são seus conselheiros, auditores, funcionários, como são escolhidos, se comportam e outras questões pertinentes para compreender o poder, a estrutura e o funcionamento desta instituição. O artigo está dividido em quatro partes. A primeira trata das funções da instituição, a segunda sobre sua estrutura funcional, a terceira sobre aspectos históricos e políticos e, por fim, as conclusões finais.
\end{abstract}

Palavras-chave: Tribunal de Contas. Família. Paraná.

\section{COURT OF ACCOUNTS OF PARANÁ: INSTITUTION, POLITICS AND HISTORY}

(1947-2017)

\begin{abstract}
Resumo: Na Sociologia e na Ciência Política brasileira nota-se que existe um grande foco na pesquisa sobre os poderes Executivos e Legislativos, seja federal, estadual ou municipal. Entretanto, o poder Judiciário e as instituições de controle, como o Tribunal de Contas e o Ministério Público, são pouco pesquisadas. Neste artigo proponho uma análise do Tribunal de Contas do Paraná, com foco em seus aspectos funcionais e políticos, para encontrarmos sua articulação com a história do Paraná. Trata-se de uma instituição com pouca exposição social, sem muito destaque na opinião pública local. Apesar de ser popularmente conhecido como local de coagulação de disputas e deliberações acerca de aspectos relevantes da vida política estadual e municipal, muito pouco se sabe sobre o poder que o Tribunal de Contas exerce sobre os outros poderes e sobre a sociedade, quem são seus conselheiros, auditores, funcionários, como são escolhidos, se comportam e outras questões pertinentes para compreender o poder, a estrutura e o funcionamento desta instituição. O artigo está dividido em quatro partes. A primeira trata das funções da instituição, a segunda sobre sua estrutura funcional, a terceira sobre aspectos históricos e políticos e, por fim, as conclusões finais.
\end{abstract}

Palavras-chave: Tribunal de Contas. Família. Paraná.

- Enviado em 15/07/2017

- Aprovado em 28/07/2017

\footnotetext{
${ }^{1}$ Doutorando em Sociologia pela Universidade Federal do Paraná.
}

Uma versão preliminar desse texto foi apresentada no $18^{\circ}$ Congresso Brasileiro de Sociologia. Que Sociologia fazemos? Interfaces com contextos locais, nacionais e globais realizado de 26 a 29 de julho de 2017 no Centro de Convenções Ulysses Guimarães, Brasília/DF. 


\section{Função do Tribunal de Contas do Paraná}

Nos primeiros anos da Corte, a partir de 1947, devido a pouca estrutura física e técnica, a grande preocupação foi estruturá-la para exercer seu papel fiscalizador. Vêm desta época as primeiras regras e instruções para a análise dos processos e para a organização das atribuições do Tribunal de Contas. Durante as décadas de 1950 e 1960 o Tribunal sofreu alterações em sua organização e competência. O número de juízes - que passaram a ser chamados ministros - subiu de cinco para sete, com igual número de suplentes. Também foi criada a vaga de auditor, com sete vagas. Até ser outorgada a Constituição Federal de 1967, o TCE-PR detinha, entre outras competências, a atribuição de acompanhar a execução orçamentária, registrar previamente as despesas e os contratos, além de julgar as contas dos responsáveis por bens e dinheiro públicos. O então governador Paulo Pimentel manteve a competência de análise a priori dos gastos do dinheiro público. Conforme Pimentel, o registro prévio dos gastos "para mim não atrapalhava nada. Pelo contrário, me dava tranquilidade, pois quando a despesa era paga ou quando as obras eram iniciadas, tudo já havia sido examinado pelo TC". Apenas depois, a partir de 1971, houve uma significativa alteração na forma de atuação do Tribunal de Contas, passando de um controle preventivo, que precedia às contratações públicas, para um controle repressivo, posterior à concretização do ato pela Administração.

Com a promulgação da Constituição Federal de 1988, os Tribunais de Contas ganharam competências e foram fortalecidos. O modelo de controle externo a posteriori foi mantido pela Constituição Federal de 1988 e houve uma ampliação do campo de atuação do Tribunal, recebendo poderes para exercer a fiscalização contábil, financeira, orçamentária, operacional e patrimonial. Houve alargamento no rol daqueles que devem prestar contas, abrangendo pessoas físicas e jurídicas, públicas ou privadas, todas as entidades da administração direta e indireta, incluindo as fundações e sociedades instituídas e mantidas pelo poder público. O TCE-PR ganhou amplas atribuições, provocando maiores impactos no Poder Executivo do Governo Estadual, na Assembleia Legislativa, no Judiciário e em todo campo das políticas públicas dos 399 Municípios do Paraná, empresas e outras esferas da vida cotidiana da sociedade paranaense. O TCE-PR fiscaliza as contas do Governador, dos chefes da Assembleia Legislativa, Tribunal de Justiça, Ministério Público, Controladoria Geral, Defensoria Pública e do próprio Tribunal de Contas, além dos prefeitos e presidentes de câmaras municipais. Também fiscaliza empresas estatais e mistas (Sanepar, Copel, 
Compagás, etc), secretarias estaduais e municipais, Porto de Paranaguá, autarquias, universidades estaduais, fundos, fundações, entidades do terceiro setor, entre outros órgãos. São mais de 2 mil entes públicos e privados que são fiscalizados atualmente pelo TCE-PR.

\section{Estrutura funcional do TCE-PR}

Atualmente o corpo diretivo e operacional do TCE-PR é integrado pelos conselheiros, auditores e procuradores do Ministério Público de Contas, dispondo de uma estrutura técnica com pouco mais de 600 funcionários. O corpo deliberativo do TCE-PR é um colegiado de Conselheiros, o Tribunal Pleno, formado por sete membros com cargo vitalício. Quatro deles são escolhidos pela Assembleia Legislativa e três pelo chefe de governo estadual. Das cadeiras do governo estadual, apenas uma é de livre escolha. As outras duas vagas estão vinculadas à lista tríplice, uma do Ministério Público e outra da carreira de auditores.

Os Conselheiros concentram o poder político do Tribunal e possuem vantagens consideráveis: tem as mesmas garantias, prerrogativas, impedimentos, vencimentos e vantagens dos desembargadores do Tribunal de Justiça. Os conselheiros do TCE-PR, como os altos funcionários do Estado, estão situados junto com desembargadores, por força de dispositivo constitucional.

31 conselheiros que integraram o Tribunal Pleno entre 1947 e 2016. São eles: Raul Vaz, Raul Viana, Caio Graccho Machado Lima, Brasil Pinheiro Machado, Daniel Borges dos Reis, Eugênio José de Souza, Lauro Rego Barros, Algacyr Guimarães, Nacim Bacilla Neto, Leônidas Hey de Oliveira, José Isfer, Antônio Ferreira Rüppel, Rafael Iatauro, João Féder, Armando Queiróz de Moraes, Cândido Manuel Martins de Oliveira, João Olivir Gabardo, João Cândido Ferreira da Cunha Pereira, Nestor Baptista, Quielse Crisóstomo da Silva, Artagão de Mattos Leão, Henrique Naigeboren, Heinz Georg Herwig, Fernando Augusto Mello Guimarães, Caio Marcio Nogueira Soares, Hermas Eurides Brandão, Maurício Requião de Mello e Silva, Ivan Lelis Bonilha, José Durval Mattos do Amaral, Fábio de Souza Camargo e Ivens Zschoerper Linhares.

Os auditores substituem os conselheiros quando precisam por motivos de licenças, férias, vacância ou outro afastamento legal. Até 2003, quando ocorre o primeiro concurso para auditores realizado pelo TCE-PR, as indicações eram, em grande medida, de caráter político. Atualmente, são quatro os auditores empossados em decorrência de concurso público: Cláudio Canha, Sérgio 
Fonseca, Thiago Cordeiro e Tiago Pedroso. Já foram auditores, desde 1947, Nacim Bacilla Neto, José Isfer, Elis Karan, Alceu Ribeiro de Macedo, Fernando Flores, Julio Farah, Aloysio Blasi, José Theodoro Miró Guimarães, José de Almeida Pimpão, João Antonio Braga Cortes, Gabriel Baron, Lauro Schleder, Erasmo Pilotto, Paulo Mercer Carneiro, Amaury de Oliveira e Silva, Cândido Machado de Oliveira Netto, Emílio Hoffman Gomes, Antonio Brunetti, Renato Loures Bueno, Newton Luiz Puppi, Saul Raiz, Ivo Thomazoni, Felipe Aristides Simão, Joaquim de Almeida Peixoto, Fabiano Saporitti Campelo, Nagibe Chede, Goyá Campos, Marins Alves de Camargo Neto, Roberto Macedo Guimarães, Francisco Borsari Netto, Joaquim Antonio Amazonas Penido Monteiro, Ruy Baptista Marcondes, Oscar Felipe Loureiro do Amaral, Jaime Tadeu Lechinski, Caio Márcio Nogueira Soares, Eduardo Souza Lemos e Ivens Zschoerper Linhares.

Os procuradores que integram o Ministério Público de Contas emitem pareceres preliminares e sobre o mérito dos processos, denúncias e representações julgados pelo Tribunal de Contas. São chefiados pelo procurador-geral que possui o mesmo tratamento jurídico e protocolar dos conselheiros. Os procuradores-gerais foram Ney Leprevost, José Pires Braga, Ezequiel Honório Vialle, Odilon Túlio Vargas, Ivan Xavier Vianna, Osvaldo Evangelista de Macedo, Rodolfo Purpur, Horácio Raccanello Filho, João Bonifácio Cabral Júnior, Henrique Naigeboren, Lauri Caetano da Silva, Luiz Carlos Caldas, Fernando Augusto Mello Guimarães, Katia Regina Puchaski, Gabriel Guy Léger, Angela Cassia Costadello, Elizeu de Moraes Corrêa, Laerzio Chiesorin Júnior e Michael Richard Reiner.

O TCE-PR também conta com uma estrutura técnica com servidores, funcionários técnicos e aposentados, atualmente ligados ao ParanáPrevidência.

\section{História e política do TCE-PR}

O Tribunal foi criado em 2 de junho de 1947, através do Decreto-Lei estadual $n^{\circ} 627$ do então governador do Estado, Moysés Lupion. Funcionava então na Rua Ermelindo de Leão, em casa que hoje fica a Polícia Civil. O corpo deliberativo era formado por uma representação da Secretária da Fazenda do Estado e cinco juízes. Foram escolhidos pelo governador Moisés Lupion os juízes Raul Vaz, Daniel Borges dos Reis, Brasil Pinheiro Machado, Raul Viana e Caio Graccho Machado Lima. 
Em 12 de agosto de 1947 é aprovado o primeiro Regimento Interno da Casa, versando sobre sua constituição e estabelecendo procedimentos de trabalho a serem adotados. Com 74 artigos, foi assinado pelos cinco juízes do Tribunal. A eleição de seus primeiros dirigentes ocorreu em 14 de julho de 1947, levando Raul Vaz à presidência (fato que se repetiria por mais 15 vezes em sua carreira) e Daniel Borges dos Reis à vice-presidência.

Quase todos os juízes indicados eram ligados ao então primeiro governo Lupion, que começara em 12 de março de 1947, menos de três meses antes do Decreto de fundação do Tribunal. Raul Vaz era diretor do jornal lupionista "O Dia”. No Governo Lupion ocupou os cargos de Diretor Geral do Departamento de Municipalidade e secretário estadual do Interior e Justiça. Caio Graccho Machado de Oliveira Lima, filho de Vicente Machado, foi jornalista e diretor do jornal O Dia. Raul Viana era da Secretaria de Agricultura, Indústria e Comércio de Lupion e diretor do jornal "trabalhista" Diário Popular, impresso nas oficinas do jornal O Dia. Daniel Borges dos Reis foi secretário do Palácio do Governo de Lupion. O único que não era de seu grupo político era Brasil Pinheiro Machado, Interventor Federal do Paraná que foi derrotado por Lupion nas eleições de 1947 e posteriormente indicado para Juiz do TC.

Desde sua fundação em 1947 podemos compreender o papel político do Tribunal de Contas do Paraná. Nos últimos 70 anos ele está presente permanentemente nas diferentes articulações da classe dominante paranaense.

Após o governo Lupion, o TCE-PR passa a incorporar novas realidades políticas. Nos anos 1960 o TCE-PR passa por uma renovação importante de seus conselheiros, com Lauro Rego Barros, Algacyr Guimarães, João Féder, Antônio Ferreira Rüppel, Nacim Bacilla e Rafael Iatauro. Trata-se do início de um momento de transformação política no Paraná sob a influência de Aníbal Khury, Ney Braga e Paulo Pimentel ${ }^{2}$.

Lauro Rego Barros nasceu a 4 de agosto de 1918, em Curitiba. Aos 22 anos, formou-se em Direito e foi trabalhar como promotor público no interior do Paraná, na cidade de Tibagi. Prestou concursos e trabalhou em Araucária e Rio Negro. Vindo de uma tradicional família atleticana, foi convidado pelo então governador Ney Braga para assumir a Secretaria de Educação. Lauro também administrou a Secretaria de Justiça, posteriormente atuando como diretor de penitenciária. Após o término do mandato de Ney Braga, o então presidente Paulo Pimentel assumiu o governo e manteve

\footnotetext{
2 “Uma breve genealogia de Aníbal Khury”. Anais do VII Seminário de Sociologia Política (UFPR), 2016.
} 
Lauro na administração das secretarias. Apesar do modo de trabalhar diferenciado, Lauro trabalhou mais três anos no Estado. Em seguida, assumiu o Tribunal de Contas do Paraná.

Algacyr Guimarães nasceu em Curitiba, dia 02 de janeiro de 1909, filho de Heitor Alencar Guimarães e Alda Bandeira Guimarães. Fez seus estudos em Curitiba, tendo recebido diploma de engenheiro civil pela Escola de Engenharia da Universidade Federal do Paraná. Na década de 1950 transferiu-se para São Paulo, convidado a organizar o setor de transportes da Estrada de Ferro Santos-Jundiaí. Em 1957 já era diretor de operações daquela ferrovia, destacando-se pela sua competência profissional. Em razão disso, foi nomeado membro do Conselho Nacional de Tarifas de Transportes e do Instituto Nacional Tecnológico de Pesquisas Econômicas. Em 1961, o governador Ney Braga foi buscá-lo para assumir a Secretaria do Estado da Fazenda. Quando o governador Ney Braga foi convocado para o Ministério da Agricultura e, por isso, renunciou ao cargo, foi Algacyr que assumiu o posto, sendo eleito pela Assembléia Legislativa para concluir o período governamental. Após transmitir o governo ao seu sucessor, Paulo Pimentel, assumiu a Direção Geral do DNER (Departamento Nacional de Estradas de Rodagem), nomeado pelo presidente Castello Branco, em fevereiro de 1966. Entre as obras de relevo da sua administração, destaca-se a construção e pavimentação da BR 277, inaugurada em 1967. Assumiu a presidência do Banestado em 1970, sendo nomeado, a seguir, para o Tribunal de Contas do Paraná.

Rafael Iatauro, muito próximo de Aníbal Khury, sempre presente em seus famosos cafés da manhã e almoços, tomou posse como juiz substituto no Tribunal de Contas do Paraná em 19 de agosto de 1966 passou a ministro e então conselheiro e deixou a Corte de Contas 40 anos depois, em 7 de março de 2006, quando se aposentou. Presidiu o TC paranaense por seis gestões, foi cinco vezes vice-presidente e 12 vezes corregedor-geral. Quando se aposentou foi indicado como chefe da Casa Civil do governo Requião e atualmente é presidente da ParanáPrevidência do governo Richa. Diversos membros da família Iatauro trabalham ou são aposentados pelo TCE-PR. O genro de Rafael, Fábio Camargo, foi indicado para conselheiro do TCE-PR em 2013. A família está representada no Tribunal de Contas por Gracia Maria de Medeiros Iatauro, Giovana Maria Iatauro, Rafaela Iatauro Bueno e Tatianna Cruz Bove.

Antônio Ferreira Rüppel nasceu em 1921, foi prefeito do município de Bocaiuva do Sul, na região metropolitana de Curitiba, depois foi eleito deputado estadual em 1958 e reeleito em 1962. $\mathrm{Na}$ primeira legislatura que fora eleito foi presidente da Assembleia Legislativa do Paraná e na outra foi $1^{\circ}$ secretário. Braço direito de Aníbal na ALEP, foi nomeado conselheiro do Tribunal de 
Contas em 1966, onde se aposentou. Muitos parentes de Antônio Ruppel são funcionários ou aposentados pelo TCE-PR.

João Féder, bacharel em Direiro pela UFPR, tinha larga experiência no jornalismo quando foi indicado por seu sócio, Paulo Pimentel, para ser conselheiro do TCE-PR. Féder também instalou diversos familiares no TCE-PR. O mesmo aconteceu com o jornalista e advogado Nacim Bacilla Neto.

No final dos anos 1970 e durante a década de 1980 a renovação de conselheiros atendeu a novos interesses políticos. O que se manteve foi a influência de Aníbal Khury na instituição. A ascensão política do PMDB na década de 1980 com José Richa, Roberto Requião, Álvaro Dias (sempre sob a aprovação de Aníbal) indicou como conselheiros Cândido Manuel Martins de Oliveira, João Olivir Gabardo, João Cândido Ferreira da Cunha Pereira, Nestor Baptista, Quielse Crisóstomo da Silva e Artagão de Mattos Leão.

Um novo bloco político dos conselheiros do TCE-PR se constituiu na década de 1990 com as indicações de Jaime Lerner.

Henrique Naigeboren, paulistano, é formado em Direito e Economia, com pós-graduação em Direito Administrativo. Casou-se com Clarita Lerner, irmã de Jaime Lerner. Foi homem forte de Lerner em suas administrações, como procurador do município e secretário de governo. Foi indicado por Lerner para conselheiro do TCE em 1995. Sua filha, a dentista Renata Naigeboren Benzecry, possui cargo comissionado no TCE.

Heinz Herwig nasceu em Blumenau (SC) em 1942, e é formado pela Escola de Engenharia da Universidade Federal do Paraná. Ele trabalhou em diversos órgãos na área de engenharia do Paraná, como o Departamento de Estradas de Rodagem (DER), ocupando também os cargos de secretário de Planejamento e de Urbanismo da Prefeitura de Londrina na década de 70. Em 1985 e 1997, assumiu por duas vezes a Secretaria de Transportes do Paraná, e em 1990 foi eleito deputado estadual. Coordenou campanhas de Lerner e Taniguchi. Em abril de 2000, foi nomeado para o TCE por Lerner. Em 2010 o Ministério Público denunciou Lerner e Heinz Herwig por formação de quadrilha e desvio de dinheiro público pelo "escândalo Copel/Olvepar". O dinheiro teria irrigado campanhas de aliados dele ${ }^{3}$.

3 http://www.gazetadopovo.com.br/vida-publica/youssef-diz-que-lavou-r-19-milhoes-do-caso-copelolvepar8wn7gi5drdento8k2alj4yukb 
Caio Marcio Nogueira Soares, nascido em Porto União (SC), em 05 de julho de 1944, filho de Lauro Muller Soares e Antonia Nogueira Soares. Assessorava Lerner desde o final da década de 1970. Foi Diretor-Geral do Departamento de Relações Públicas e Promoções da Prefeitura Municipal de Curitiba, incluindo Assessoria de Imprensa de 1979 a 1983. Depois, de 1983 a 1986 , foi Advogado da CIC S/A, empresa vinculada à Prefeitura Municipal de Curitiba. Em 1987 foi Diretor do Banco do Estado do Rio de Janeiro - BANERJ - Região Sul, em Curitiba. De 1988 a 1992 foi Assessor Especial do Prefeito de Curitiba. Em 1993 e 1994 foi Assessor do Instituto Jaime Lerner. De 1995 a 2000 foi Secretário Especial do Governador Jaime Lerner. Depois de uma manobra para se tornar auditor do Tribunal de Contas, foi indicado depois Conselheiro por Requião.

Hermas Eurides Brandão, nascido em 5 de maio de 1943, filho de Eurides e Ercília Fioravante Brandão, Hermas Brandão formou-se em Direito pela Faculdade Brasileira de Ciências Jurídicas do Rio de Janeiro. Empresário do setor agropecuário e serventuário da Justiça, ingressou na vida pública aos 33 anos, quando venceu em 1976 as eleições para a Prefeitura Municipal de Andirá, município do Norte Pioneiro do Paraná. Ao final de seu mandato, foi Deputado Estadual por sucessivos mandatos parlamentares nos pleitos de 1986, 1990, 1994 e 1998, período ao longo do qual exerceu, na Assembléia Legislativa, a presidências de comissões permanentes, além de ter integrado a mesa diretora, nas funções de Vice-Presidente e de Primeiro-Secretário. Entre 1995 e 1998 exerceu a função de Secretário de Estado da Agricultura e do Abastecimento no primeiro governo Lerner.

Em 2010, Roberto Requião indicou seu irmão Maurício Requião de Mello e Silva como conselheiro do TCE. Apesar de tomar posse no órgão, sua indicação foi cassada pelo Supremo Tribunal Federal (STF).

Nos governos de Beto Richa, pelo menos entre 2010 e 2017, ganhou corpo novo grupo político no TCE, com as indicações de Ivan Lelis Bonilha, José Durval Mattos do Amaral, Fábio de Souza Camargo e Ivens Zschoerper Linhares.

Ivan Bonilha é advogado, graduado pela UFPR em 1989, na mesma turma de Gustavo Fruet. Em 1990, foi assessor de Maurício Fruet na Secretária de Comércio do governo Requião. Em 1993 passou em concurso para servidor do TCE. Afastou-se das atividades da Corte para trabalhar junto com o governador Beto Richa, primeiro em sua campanha em 2004 e depois sendo procurador-geral do município de Curitiba quando Richa era prefeito. Mais tarde, quando Richa se tornou governador, Bonilha assumiu o cargo de procurador-geral do Estado por seis meses. Depois, Richa indicou Bonilha 
para o cargo de conselheiro na vaga de Maurício Requião. Bonilha foi presidente do TCE no biênio 2015-2016.

Durval Amaral é natural de Londrina, no Norte do Paraná. Advogado, foi professor da Universidade Estadual de Londrina (UEL). Foi eleito vereador e vice-prefeito de Cambé e deputado estadual por seis mandatos. Como deputado, atuou como Secretário de Estado do Trabalho e Ação Social (1992-1994) no primeiro governo de Roberto Requião (PMDB). Na Assembleia Legislativa do Paraná, já foi líder do Governo Lerner (2001-2002) e líder da Oposição (2003-2005). Foi chefe da Casa Civil do primeiro governo Richa. Tomou posse como conselheiro do TCE-PR em 28 de maio de 2012. É o presidente do TCE no biênio 2017-2018.

Ao vencer a eleição em 2010, Richa nomeou Durval como seu secretário da Casa Civil - o posto mais importante do governo do estado. Depois toda a base de Richa votou em Durval Amaral para conselheiro do TCE-PR. Depois da eleição de Durval, Richa passou a fazer campanha ao lado do filho do ex-deputado, Tiago Amaral, eleito deputado estadual em 2014. O novo deputado também está na base de Richa na Assembleia.

O nome de Durval e de seu filho Tiago Amaral, eleito deputado estadual em 2014, foram citados no escândalo da Valor Construtora, empreiteira encarregada de contratos de mais de 20 milhões de reais para a construção de escolas no Paraná. As campanhas de Richa e dos deputados Ademar Traiano (PSDB) e Plauto Miró (DEM) também foram citadas no caso. Em outubro do ano passado, o doleiro Alberto Youssef e o advogado Antonio Carlos Brasil Fioravante Pieruccini afirmaram em depoimento que o então deputado estadual, em 2002, seria o encarregado da distribuição de dinheiro entre parlamentares da Assembleia por conta do esquema Copel/Ovelpar. A fraude envolveria a habilitação de créditos de ICMS de forma irregular ${ }^{4}$.

Ivens Zschoerper Linhares é advogado, colega de Bonilha no curso de Direito da Universidade Federal do Paraná (UFPR). É especialista em Direito Público também pela UFPR. Passou pelo Tribunal de Alçada do Estado, Tribunal de Justiça e Procuradoria Geral da Fazenda antes de se tornar auditor no Tribunal de Contas do Paraná por meio de concurso público, em 2005. Em 2014, o governador Beto Richa escolheu Ivens como conselheiro a partir da lista tríplice, passando ocupar a vaga que era de Caio Nogueira Soares, aposentado compulsoriamente aos 70 anos.

Fabio Camargo é natural de Curitiba, membro da tradicional família Camargo. Neto do expresidente do Tribunal de Justiça do Paraná, Desembargador Helianto Camargo, filho do

4 http://www.gazetadopovo.com.br/vida-publica/youssef-e-delator-dizem-que-durval-amaral-recebeu-de-esquema-nacopel-36y6jnxc17mpxofyxmw6ayylt 
Desembargador Clayton Camargo (eleito Presidente do Tribunal de Justiça para o biênio 2013/2014), e genro do ex-conselheiro do Tribunal de Contas, Rafael Iatauro. Parente do exDeputado Federal Affonso Alves Camargo Neto, ex-Senador, Ex-Ministro e neto do Presidente do Paraná, por duas vezes na República Velha, Affonso Alves Camargo. Sua irmã Vanessa Camargo é juíza.

Logo ao ter iniciado seu curso de Direito na Universidade Tuiuti, Fábio passou para Assessoria Jurídica do TJ. Foi convidado a participar da Procuradoria do Município, onde começou seu contato com a política. Em 1998 assumiu a diretoria de Marketing da Paraná Turismo do Governo Lerner. Em 2000, Fabio Camargo elegeu-se Vereador de Curitiba pelo PSC, com quase 9 mil votos. Em 2002, Fabio Camargo concorre a Deputado Estadual pela primeira vez, obtendo 34 mil votos e ficando como suplente. Em 2004, reelege-se vereador com 18 mil votos, a terceira maior votação da capital paranaense. Com quase 39 mil votos, Fabio elege-se Deputado Estadual em 2006. Em 2010, é reeleito para seu $2^{\circ}$ mandato como Deputado Estadual pelo PTB, com 37.786 votos.

Em 16 julho de 2013 renunciou ao mandato de deputado estadual para assumir a vaga de Conselheiro do Tribunal de Contas do Paraná. Na época de sua eleição para o TC, o então corregedor do CNJ, Francisco Falcão, chegou a citar denúncias de que Camargo e o pai tivessem usado tráfico de influência para que o ex-deputado chegasse ao $\mathrm{TC}^{5}$. Fábio Camargo foi eleito para o TCE na vaga deixada por Hermas Brandão, que se aposentou compulsoriamente, aos 70 anos. A indicação foi aprovada por 27 dos 54 deputados estaduais. O segundo colocado foi o $1^{\circ}$ secretário da Assembleia Legislativa, Plauto Miró Guimarães (DEM). Inicialmente, Plauto era o favorito, já que garantia ter o apoio do governador Beto Richa (PSDB) para a vaga. Mas a apresentação do nome de Camargo abalou o projeto do $1^{\circ}$ secretário da Assembleia Legislativa que, após a derrota, chegou a fazer um discurso em plenário afirmando que havia sido usado num jogo de interesses entre o Palácio Iguaçu e o Tribunal de Justiça. Ele se referia ao projeto de iniciativa comum do Tribunal de Justiça e do governo do Estado que transfere para o caixa único do governo $30 \%$ dos depósitos judiciais. O projeto foi aprovado em convocação extraordinária dos deputados estaduais, durante o recesso parlamentar e dez dias após a eleição de Camargo para conselheiro do Tribunal de Contas do Estado. Segundo denúncias, tratamento diferenciado aos processos que alguns deputados respondem na Justiça também fariam parte do pacote que teria levado Fábio Camargo ao TCE.

\footnotetext{
$5 \mathrm{http}: / /$ www.gazetadopovo.com.br/vida-publica/cnj-investiga-suspeita-de-trafico-de-influencia-na-eleicao-do-tc-pr48s 3j73smuu73yu1t5et5csb2
} 


\section{Considerações finais}

O TCE-PR é uma instituição crucial para compreender a política do Paraná, presente na condução de interesses políticos estaduais por 70 anos, desde sua fundação em 1947. O que procuramos demonstrar neste artigo (e o leitor agora pode tirar suas próprias conclusões) é que, em especial por meio de seus Conselheiros, o TCE-PR exerce um papel político muito importante e por vezes negligenciado. Todas as indicações são notadamente baseadas em acordos com o governo estadual. Quando se aprofunda sobre seu papel institucional, percebe-se que o Tribunal de Contas é um espaço privilegiado na disputa política e a sua relação com os outros poderes do Estado, um locus privilegiado na ação das classes dominantes. A pesquisa deve avançar no sentido de montar o complexo tecido relacional dos conselheiros, auditores e funcionário, permitindo analisar a dinâmica do poder do TCE-PR, sua inserção no ambiente político, identificar os padrões de relacionamento entre os poderes, suas mudanças no tempo e presença da instituição na esfera política.

\section{Bibliografia consultada}

DELGADO, José Augusto. Os Tribunais de Contas e sua importância institucional. Origem. Os Tribunais de Contas nas instituições da Alemanha, Argentina, Chile, Espanha e Portugal. Relação, no Brasil, com a Lei de Responsabilidade Fiscal. Curitiba: Juruá, 2006.

FAGUNDES, Seabra. O controle dos atos administrativos pelo Poder Judiciário. 4. ed. Rio de janeiro, Forense, 1967.

FERREIRA, Luciane Fleck. O poder de polícia dos tribunais de contas. Monografia do curso de especialização em gestão pública e controle externo. Tribunal de Contas do Rio Grande do Sul. Porto Alegre, 2008.

GUERRA, Evandro Martins. Os controles externos e internos da Administração Pública e os Tribunais de Contas. Belo Horizonte: Fórum, 2003. 
JAYME, Fernando G. Tribunal de Contas: jurisdição especial e a prova no procedimento de julgamento de contas. In: Revista do Tribunal de Contas de Minas Gerais. Be lo Horizonte. v.32. n.3. p.135-150. jul./set. 1999. p. 135-150.

MEDAUAR, Odete. Controle da Administração Pública. São Paulo: Revista dos Tribunais, 1993.

MILESKI, Helio Saul. O controle da gestão pública. São Paulo: Revista dos Tribunais. 2003.

MIRANDA, Francisco Cavalcanti Pontes de. Comentários à Constituição de 1967 com a Emenda n. 1, de 1969. São Paulo: Revista dos Tribunais, 1973.

OLIVEIRA, Ricardo Costa de. O silêncio dos vencedores. Genealogia, classe dominante e Estado no Paraná. Curitiba: Moinho do Verbo, 2001.

Na teia do nepotismo: sociologia política das relações de parentesco e poder político no Paraná e no Brasil. Curitiba: Insight, 2012.

Política, Direito, Judiciário e Tradição Familiar. IX Encontro das ABCP, 2014.

TORRES, Ricardo Lobo. O Tribunal de Contas e o controle da legalidade, economicidade e legitimidade. Rio de Janeiro: Revista do TCE/RJ, n. 22, jul/1991. 